\title{
Seasonal Variations of the Urban Heat Island in Kumagaya, Japan
}

\author{
NAKAMURA Yusuke*, SHIGETA Yoshinori** and WATARAI Yasushi*** \\ * Graduate School of Geo-environmental Science, Rissho University; Saitama 360-0194, Japan. \\ ** Faculty of Environmental Studies, Tottori University of Geo-environmental Science; Tottori 689-1111, Japan. \\ *** Faculty of Geo-environmental Science, Rissho University; Saitama 360-0194, Japan. \\ E-mail:169w00002@rissho-univ.jp*
}

Received August 2, 2017; Accepted August 9, 2018

\begin{abstract}
The seasonal variations of the urban heat island (UHI) phenomenon in Kumagaya, Japan were examined using multiple fixed-point observations of surface air temperature during a 1-year period. Horizontal distributions of surface air temperature observations in Kumagaya showed that UHI occurs continuously. The hourly average temperature difference between urban and rural areas was constant at $\sim 1^{\circ} \mathrm{C}$. The UHI intensity (UHII) was calculated by dividing all observation points into urban and rural areas. Seasonal variation of daytime UHII was observed in Kumagaya, with maximum and minimum values in summer and winter, respectively. The observation of specific humidity during sunny days in summer suggested that the difference in the surface heat balance between urban and rural areas greatly contributed to the temperature difference between the two areas. Nighttime UHII in Kumagaya was the highest during April-May. These observations of maximum UHII may be explained by strong northwesterly flow over the mountains during winter and frequent calm and sunny days due to migratory anticyclone during April-May.
\end{abstract}

Key words urban heat island, urban climate, seasonal variations, multiple fixed-point observations of air temperature, Kumagaya city

\section{Introduction}

The urban heat island (UHI) phenomenon arises from urbanization, making it a common issue for humans in the 21 st century. UHI causes the surface air temperature in urban areas to be higher than that in surrounding rural areas. Impacts of UHI may include changes in energy consumption (Kikegawa et al. 2006), health effects such as heat stroke and sleeping disorders (Tan et al. 2010), and ecosystem changes (Shochat et al. 2006). Oke (1978) summarized the UHI formation mechanisms as follows. In urban areas, there are (1) increase in short wave radiation absorption, (2) increase in long wave radiation from the atmosphere, (3) decrease in long wave radiation loss, (4) increase in anthropogenic heat, (5) increase in sensible heat accumulation, (6) decrease in evaporation, and (7) decrease in turbulent heat transport.

Numerous studies report that UHIs are most likely to develop on clear nights. UHI studies frequently use the urban heat island intensity (UHII) as a quantitative index of the UHI intensity and frequency. UHII is generally defined by the temperature difference between urban and rural areas. Previous studies have discussed relationships between UHII and weather conditions (Oke and Maxwell 1975), pop- ulation size (Oke 1973), and the sky view factor (Oke 1981).

It is important in considering future urban design to investigate how the UHI in a city changes with local climate. On the other hand, most of the previous studies target sunny days for the purpose of elucidating the UHI mechanism. However, UHI is greatly affected by the synoptic and local climate zone of the area where each city is located (for example, Chow and Roth 2006). Therefore, it is important to investigate the seasonality of UHI in cities of interest, which involves consideration of all weather conditions. The study of UHI seasonality will benefit people living in each city.

In this study, climatological characteristics of UHI are investigated in Kumagaya, Saitama Prefecture. The urban climate in Kumagaya has been a topic of UHI study for the past half-century because of the flat topography, distance from both mountains and ocean, and clearly defined boundary between urban and rural areas (Kawamura 1964). For example, Matsumoto et al. (2002) suggested that the UHI in Kumagaya is closely related to the morphology of urban area and the thermal properties of the ground surface. Kuwagata et al. (2014) performed fixed-point meteorological observations in rural Kumagaya and suggested that the temperature at the 
Kumagaya Meteorological Observatory (which is located in an urban area) was consistently higher than that in rural areas. This trend was particularly predominant during the daytime in summer. However, previous studies mostly involved a single-point observation or a specific and time-limited mobile observation, and detailed studies of the UHI horizontal structure and climatological characteristics have not yet been carried out. Discussion of UHIs in terms of only one observation point may be misleading because UHIs often have complicated horizontal structures. For example, Kusaka et al. (2012) and Nakamura and Shigeta (2014) suggested that the temperature dispersion inside an urban area might be as large as the urban-rural temperature difference. Thus, using only one point observation can create bias in UHI calculations.

The literature summarized above suggests that the long-term observation with high spatial density and temperature continuity is necessary in order to discuss the characteristics of UHI in each city with any precision. These observations can capture the seasonal variations of UHI considering the spatial extent of each city. Therefore, based on the long-term multiple fixed-point observations, the horizontal distributions of surface air temperature in Kumagaya are investigated in this study. Moreover, UHI intensity was calculated using multipoint air temperature data, and the diurnal variation in each month is discussed. Further, seasonal variations and climatological characteristics of the UHI around Kumagaya are also examined. Finally, the paper was concluded by comparing these results with previous studies.

\section{Study Methods}

Kumagaya can be characterized as a mid-sized city with an area of $\sim 160 \mathrm{~km}^{2}$ (Figure 1) and a population of $\sim 200,000$ located in the northwestern part of the Kanto plain in Japan. Variations in elevation are small in and around Kumagaya. The southern part of Kumagaya include a hill of $50 \mathrm{~m}$ in elevation. However, $80 \%$ of the surrounding area is level ground with an elevation of $\sim 30 \mathrm{~m}$. The land use distribution in the area is shown in Figure 2. The Arakawa River runs from west to east along the southern edge of the Kumagaya urban area. The area around Kumagaya Station contains commercial and office blocks with numerous buildings, such as the city hall. In the northern part of the city, the land cover primarily consists of paddies. The southern area has quite different land cover, which is dominated by forests and crop fields.

The characteristic climatology of the city can be explained as follows. Japan has four seasons and a warm and humid climate in summer. The annual average values of temperature, relative humidity and precipitation in a normal year are $15.0^{\circ} \mathrm{C}, 66 \%$ and $1236.3 \mathrm{~mm}$ in Kumagaya. Kumagaya is located in the northwestern Kanto Plain, which experiences temperature and humidity increases under the influence of southerly winds from the North Pacific High during summer. In summer, daytime temperature in Kumagaya is often very high in part due to the foehn phenomenon (Takane and Kusaka 2011). In winter, on the other hand, northwestern Kanto experiences a strong northwesterly wind under the influ-

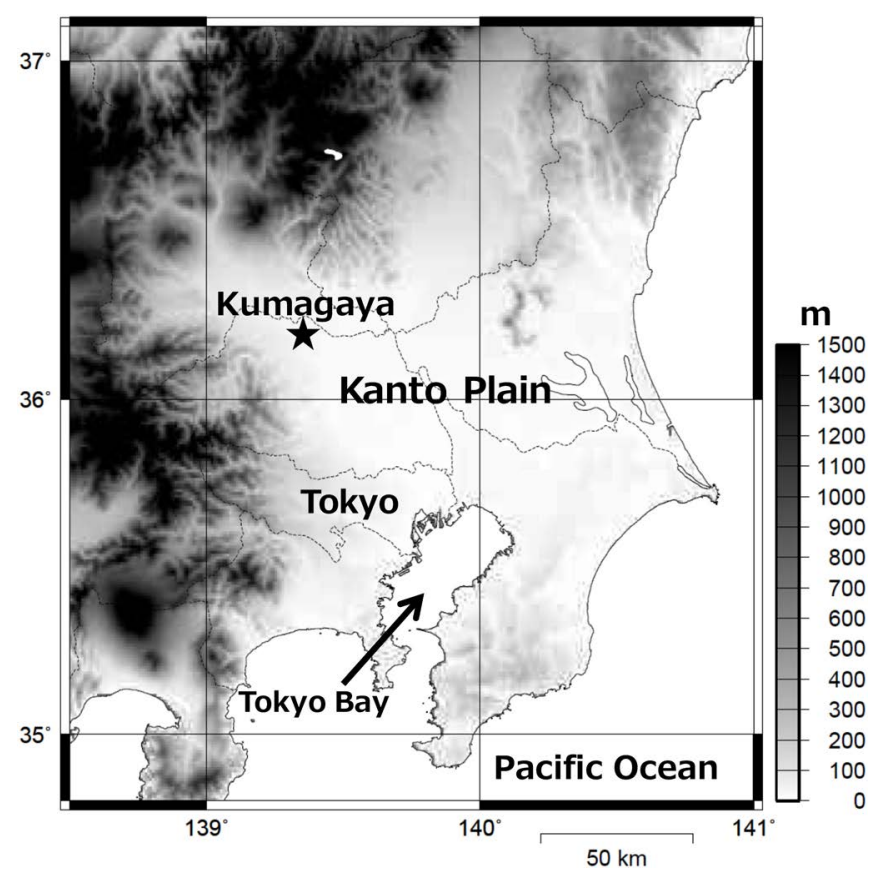

Figure 1. The location of Kumagaya in the Kanto Plain. 


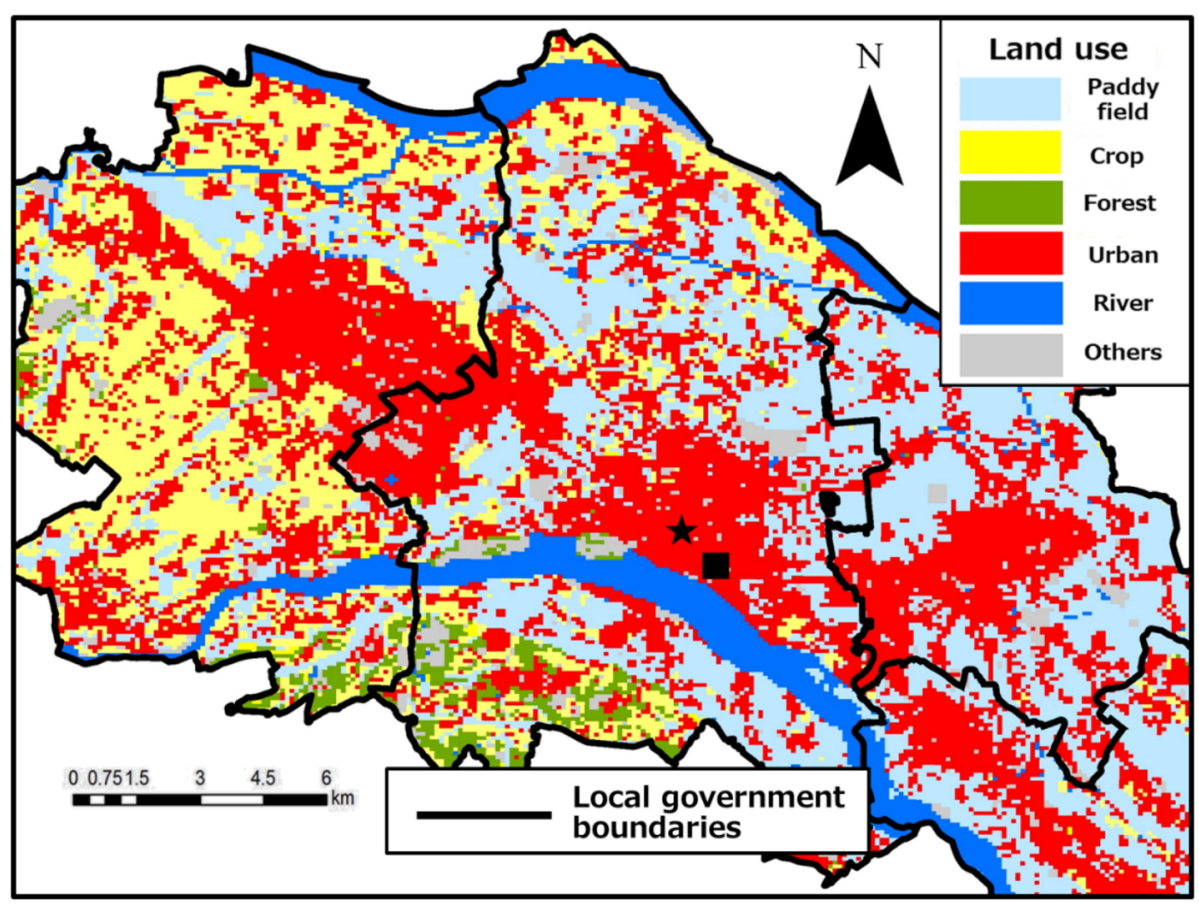

Figure 2. The land use around Kumagaya. Symbol $\square$ denotes Kumagaya Station, and $\star$ the Kumagaya Meteorological Observatory.

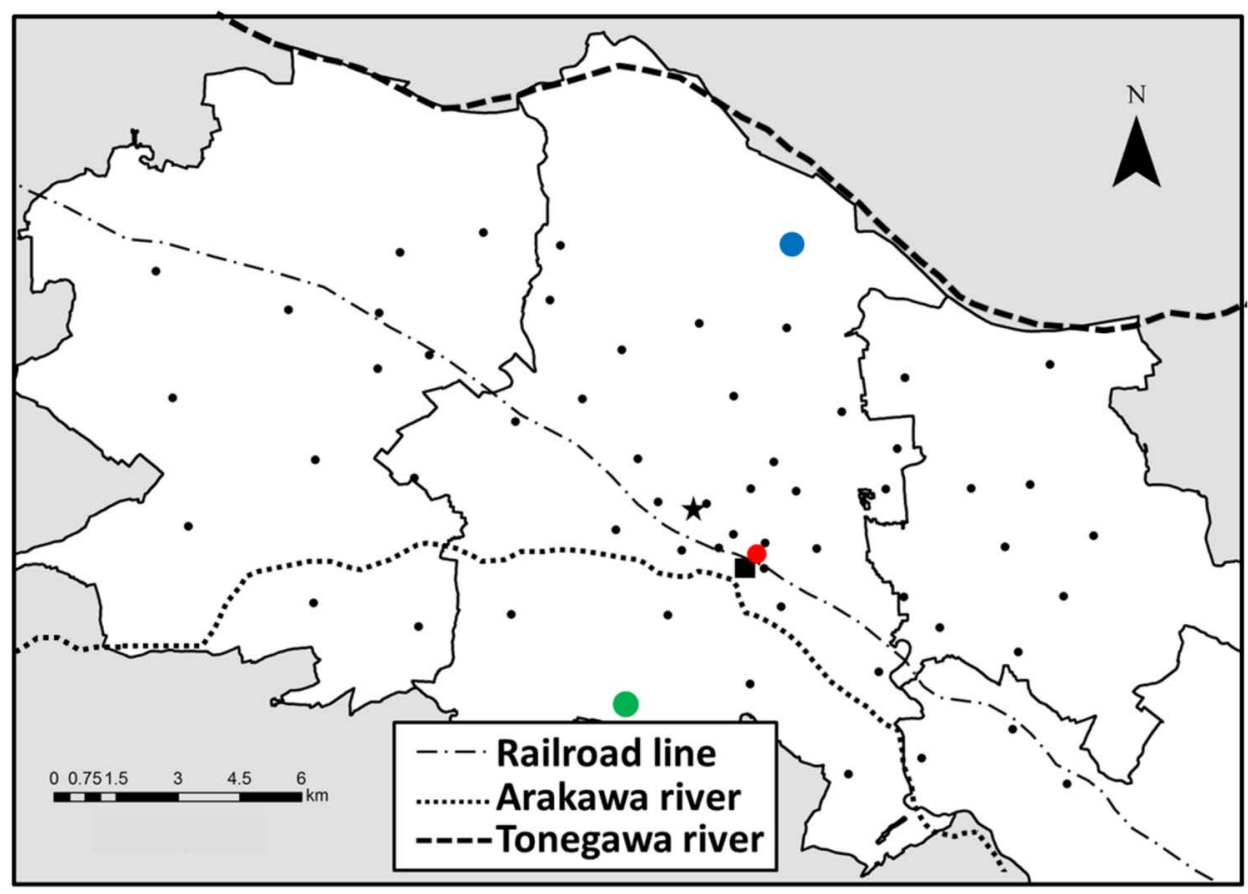

Figure 3. Observation points of this study (dots), and representative points in the urban (red), the northern-rural (blue) and the southern-rural (green) areas. Symbol $\mathbf{d e n o t e s ~ K u m a g a y a ~ S t a t i o n , ~ a n d ~} \star$ the Kumagaya Meteorological Observatory.

ence of winter monsoons, with many dry and sunny days.

The observation of surface air temperature was performed at 56 fixed points within $20 \mathrm{~km}$ in the east-west direction and $16 \mathrm{~km}$ in the north-south direction (Figure $3)$. Observation points were selected to include the various land-use types within Kumagaya. The observation was performed from March 1, 2014 to February 28, 2015.
The missing rate was $0.2 \%$. We used temperature sensors (RTR-502: T\&D company) in natural ventilation shelters (Shigeta and Ohashi 2009). The observation equipment was installed on a pole located in the park, at a height of approximately $2.5 \mathrm{~m}$ above ground level. Measurements were taken at two-minute interval. Ten-minute average values were used for the analysis herein after smoothing 


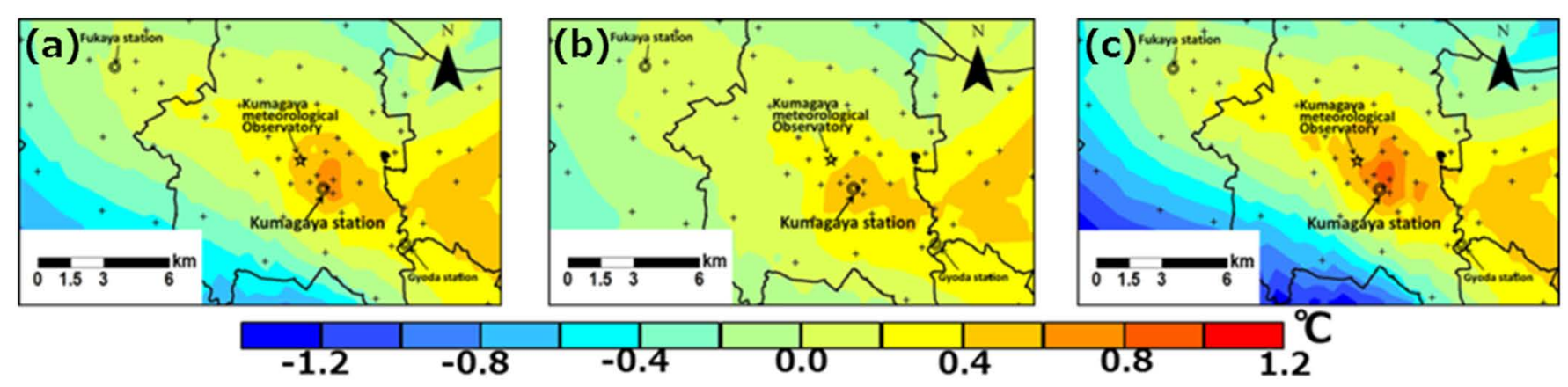

Figure 4. Horizontal distributions of the annual average surface air temperature anomaly.

(a) daily average, (b) daytime average, (c) nighttime average.

using a twenty-minute running mean. Meteorological data of the Kumagaya Meteorological Observatory (located in the center of the observation area) were also used for the analysis.

\section{Horizontal Distributions of Surface Temperature}

\section{Annual average}

Figure 4 shows horizontal distributions of the surface air temperature anomaly (from the spatial average) for daytime, nighttime, and daily average. Daytime and nighttime are defined by time from sunrise to sunset, and from sunset to sunrise, respectively. For the daily average, the highest-temperature observation point was found in the urbanized area to the north of Kumagaya Station (Figure 4-a). Concentric isotherms around the urban area formed a clear high-temperature anomaly (the so-called heat island). The temperature anomaly at the center of UHI was approximately $+0.6^{\circ} \mathrm{C}$. On the other hand, a low temperature anomaly of less than $-0.4^{\circ} \mathrm{C}$ appeared in the southern part of the observation area. This area primarily consisted of crop fields and forests.

The daytime average formed a belt-shaped high temperature anomaly corresponding to the urban area (Figure 4-b). However, there was neither a clear hightemperature anomaly in the urban area nor a clear lowtemperature anomaly in the rural area. The temperature anomaly is approximately $-0.4 \sim+0.4^{\circ} \mathrm{C}$. On the other hand, the spatial pattern of the nighttime temperature anomaly was similar to the pattern observed in the daily average (Figure 4-c). The high- and low-temperature anomalies were $+0.8 \sim+1.0^{\circ} \mathrm{C}$ and $-0.8 \sim-0.6^{\circ} \mathrm{C}$, respectively. The maximum temperature anomaly was higher in the nighttime than those observed in the daytime and the daily average.

These findings suggest that the urban warming constantly has influence on the surface temperature in
Kumagaya. The daily-average temperature difference between urban and rural area was $\sim 1^{\circ} \mathrm{C}$. Also, it is clear that the temperature difference is larger at nighttime $\left(1.4 \sim 1.8^{\circ} \mathrm{C}\right)$ than at daytime $\left(0.6 \sim 0.8^{\circ} \mathrm{C}\right)$.

\section{Seasonal differences}

In this section, we will examine seasonal differences in the surface air temperature. Figures 5 and 6 show the horizontal distributions of the surface air temperature anomaly (from the spatial average) during summer (June-August) and winter (December-February), respectively. In both seasons, the UHI was more apparent at night than during the daytime. During the daytime in summer, the urban area was warmer than the surrounding rural area, while the northern central part of the observation area was cooler than the surroundings (Figure 5-a). Land use in the northern central part of the observation area greatly differs from the southern area (Figure 2), which primarily consists of paddy fields. This area is generally cooler as seen in Figure 4. Daytime temperature difference of $1^{\circ} \mathrm{C}$ or more between urban and rural areas was observed only during the summer season. On the other hand, the feature of daytime anomaly characterized by high temperatures in urban areas and low temperatures in the northern area was less welldefined in winter. Daytime anomaly within the study area ranged between -0.4 and $+0.4^{\circ} \mathrm{C}$ (Figure 6-a). During nighttime, there were no significant seasonal changes in the areas showing high- and low-temperature anomalies (Figure 5-b and 6-b). The temperature difference between the maximum anomaly (located just north of Kumagaya Station) and the minimum anomaly (located on the southern side of the city) was $1.2^{\circ} \mathrm{C}$ in summer and $2.2^{\circ} \mathrm{C}$ in winter, respectively.

The findings show that the area showing high temperature anomaly was no significant seasonal changes. However, significant seasonal changes were shown in the following points. During daytime, the area showing low 


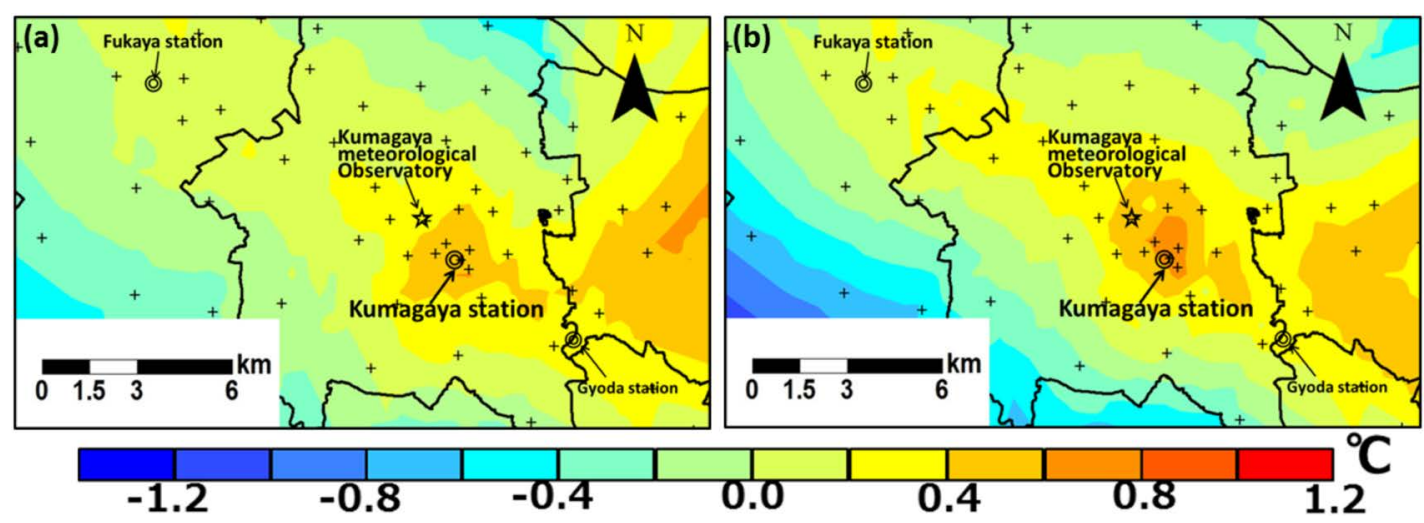

Figure 5. Horizontal distributions of the surface air temperature anomaly.
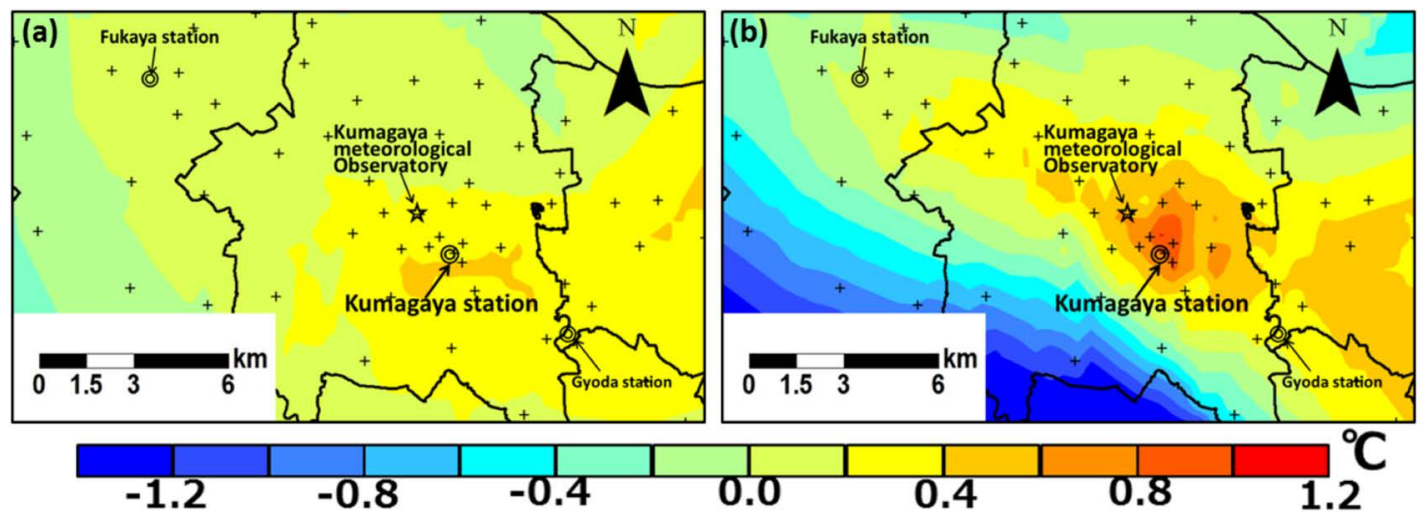

Figure 6. Horizontal distributions of the surface air temperature anomaly.

(a) daytime average, and (b) nighttime average in winter.

temperature appeared only in the summer. During nighttime, the temperature difference between the maximum anomaly and the minimum anomaly is larger approximately $1^{\circ} \mathrm{C}$ in winter than in summer.

\section{Urban Heat Island Intensity}

\section{Definition}

In this study, UHII is used as a quantitative index of the intensity and frequency of the UHI. However, UHII can vary widely depending on the selection of representative points (see for example: Sakakibara and Owa 2005; Nakamura and Shigeta 2014). Therefore, urban and rural representative points must be chosen objectively. Oku and Masumoto (2014) classified multipoint surface temperature observations to urban and rural groups using cluster analysis. In this study, cluster analysis is also used to classify all observed data of surface temperature from 56 points into urban and rural groups, resulting in two clusters. The result of the cluster analysis is plotted on the map shown in Figure 7. 27 and 29 points were assigned to Cluster $1(\mathrm{C} 1)$ and Cluster $2(\mathrm{C} 2)$, respectively. Considering the diurnal temperature variation and the

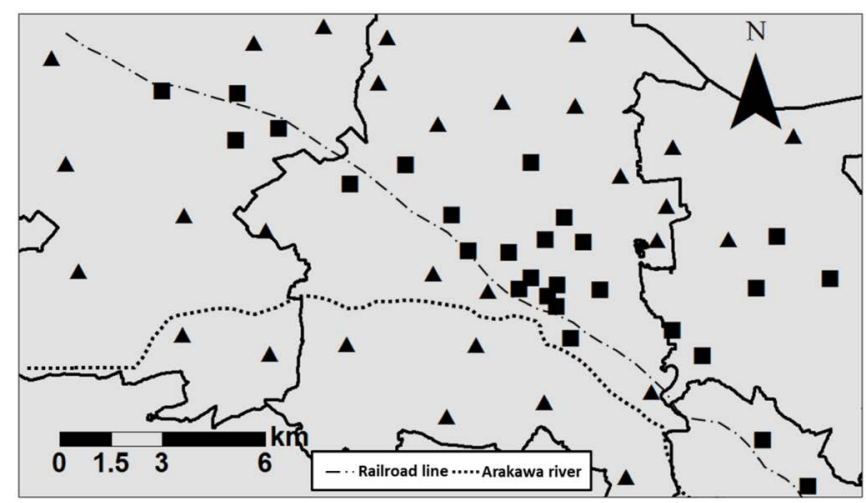

Figure 7. Map showing the result of the cluster analysis. Symbols $\boldsymbol{\square}$ and $\boldsymbol{\Delta}$ denote the Cluster 1 (C1) and 2 (C2), respectively.

land cover at each point, we determined that Clusters 1 and 2 possess urban and rural characteristics, respectively. Therefore, UHII is defined as the difference in average temperature between $\mathrm{C} 1$ (which has urban characteristics) and C2 (which has rural characteristics) in this study.

\section{Seasonal variations}

Seasonal variation of the UHII in Kumagaya is examined in this section. Figure 8 shows the seasonal variation 


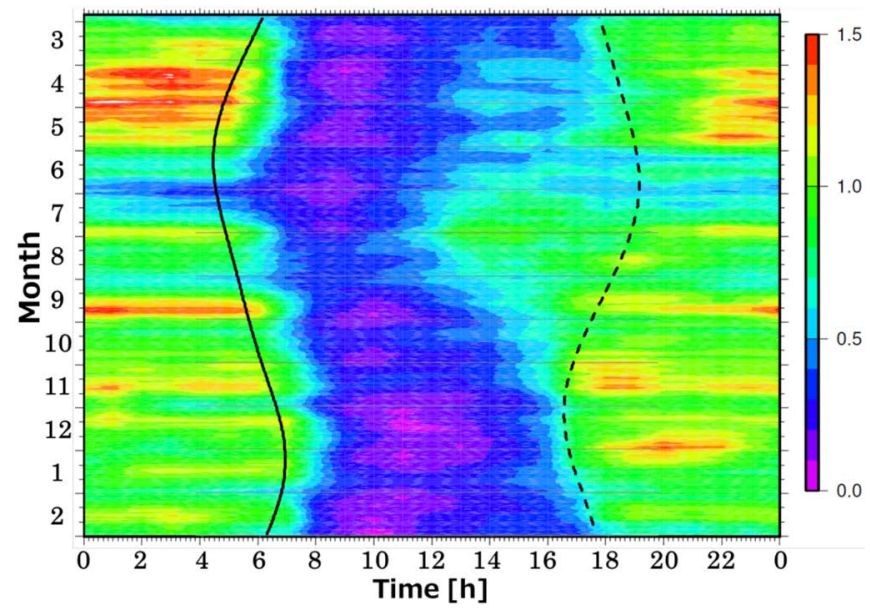

Figure 8. Seasonal variation in UHII diurnal cycles (unit: ${ }^{\circ} \mathrm{C}$ ). Solid and dashed lines indicate the sunrise and sunset times, respectively.
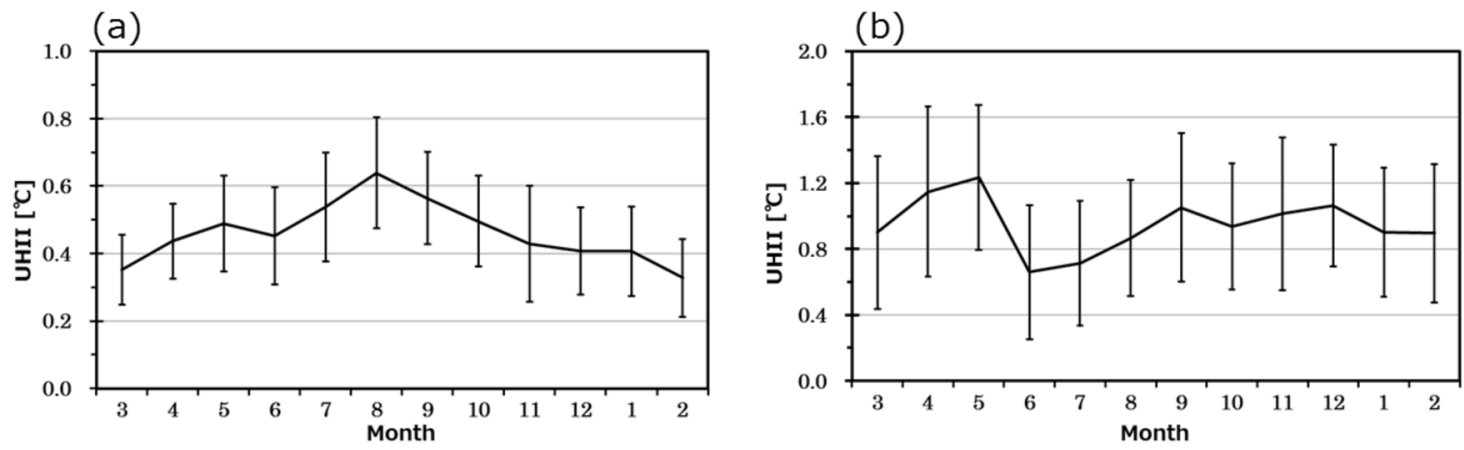

Figure 9. Seasonal variations in the monthly average UHII with standard deviations shown by error bars.

(a) daytime, and (b) nighttime.

in UHII diurnal cycles. The 15-day running mean value is shown. The UHII was higher during the nighttime than during the daytime in all seasons. The UHII increased rapidly after sunset. The UHII minimum appeared a few hours after sunrise. In most seasons, the daytime UHII was less than $0.5^{\circ} \mathrm{C}$. In November and December, the UHII was often negative (a so-called "cool island"). However, the magnitude of this negative UHII was less than $0.5^{\circ} \mathrm{C}$, which was much less than the positive UHII observed at nighttime. Conversely, the daytime UHII (and especially in the afternoon) during the warm season (June to August) measured $+1^{\circ} \mathrm{C}$ or more, distinguishing it from other seasons. This observation is in agreement with Kuwagata et al. (2014). The nighttime UHII from April to May was relatively large at values of $1.3 \sim 1.5^{\circ} \mathrm{C}$. In contrast, the nighttime UHII was smaller during the summer (and especially from mid-June to early-July), with an average UHII below $0.5^{\circ} \mathrm{C}$.

Figure 9 shows seasonal variations of monthly-mean UHII in daytime and nighttime. The error bars show the standard deviation of the UHII for each month. Daytime UHII was larger during July through September than during other months by about $0.3^{\circ} \mathrm{C}$ (Figure 9 -a). UHII maximum and minimum values were $0.6^{\circ} \mathrm{C}$ in August and $0.3^{\circ} \mathrm{C}$ in January, respectively. The nighttime UHII was larger during April and May than during other months, with a maximum of $1.2^{\circ} \mathrm{C}$ in May (Figure 9-b). In contrast, the nighttime UHII was smaller in summer, with a minimum of $0.7^{\circ} \mathrm{C}$ in June. Nighttime UHII during autumn and winter ranged between $0.9 \sim 1.1^{\circ} \mathrm{C}$ and showed no clear seasonal variation. However, the UHII became slightly smaller during October and January/ February. In addition, the monthly standard deviation was about $0.3^{\circ} \mathrm{C}$ larger in winter than in summer.

\section{Discussion}

The daytime and nighttime UHII variations in Kumagaya possess different characteristics during different seasons. Oke (1982) reviewed recent UHI studies and suggested that the factors leading to UHI formation greatly differed between daytime and nighttime. Therefore, in this section, the daytime and nighttime UHII seasonal variations are discussed separately. 


\section{Seasonal variations in daytime UHII}

This section focuses on factors that contribute to the seasonal variation of daytime UHII. In this study, we have shown that the seasonal variation of daytime UHII in Kumagaya was the largest in summer of all the seasons. We outline possible mechanisms for this below.

Ackerman (1985) who showed that the daytime UHII was higher during the summer in Chicago, USA, attributed this observation to the difference in the surface heat balance between urban and rural areas. Because the heat transport from the surface is large during sunny days, we compare seasonal variations in the sunny-day average of UHII against the all-weather average of UHII. Figure 10 shows seasonal variations in the monthly average of daytime UHII for all-weather and sunny days. A sunny day was defined herein as a day with a sunshine duration of greater than 8 hours at the Kumagaya Meteorological Observatory. Compared to the all-weather average, the sunny-day average of daytime UHII was larger in summer and smaller in spring and winter.

Additional observation of specific humidity was performed on sunny days in summer at representative points of urban, northern-rural, and southern-rural areas (Figure 3). These points were selected based on horizontal distributions of temperature and land use. The observation period spanned 8 continuous sunny days from August 6th and 13th, 2015. The average daily maximum temperature (at the Kumagaya Meteorological Observatory) during this period was $35.3^{\circ} \mathrm{C}$. Observed parameters include air temperature, relative humidity, and air pressure. Figure 11 shows 8-day average diurnal variations of specific humidity at the urban, northernrural, and southern-rural representative points. When temperature reached the daily maximum, the specific humidity at the northern and southern rural points was $1.5 \mathrm{~g} \mathrm{~kg}^{-1}$ and $1.0 \mathrm{~g} \mathrm{~kg}^{-1}$ higher than at the urban points, respectively. This is most likely due to enhanced evapotranspiration from rice paddy fields, particularly for the northern point. Therefore, it is probable that most of the net radiation is converted to latent heat, suppressing temperature increase in the surrounding area. Sakakibara (1991) also reported lower daytime surface air temperatures in paddy fields during the irrigation period.

In the following paragraphs, the daytime UHII sea-

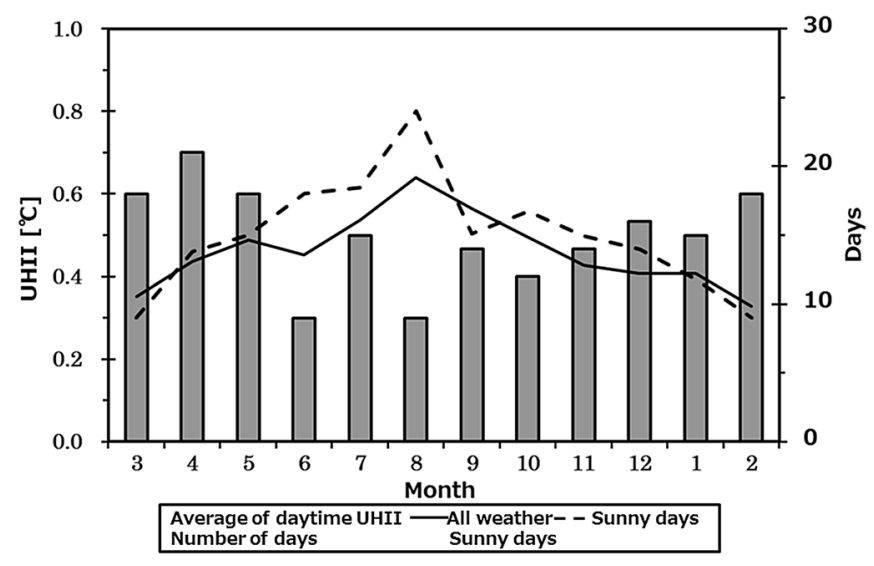

Figure 10. Seasonal variations in the monthly-mean daytime UHII averaged over all weather (solid line) and sunny days (dashed line), and seasonal variations in the number of sunny days (bar).

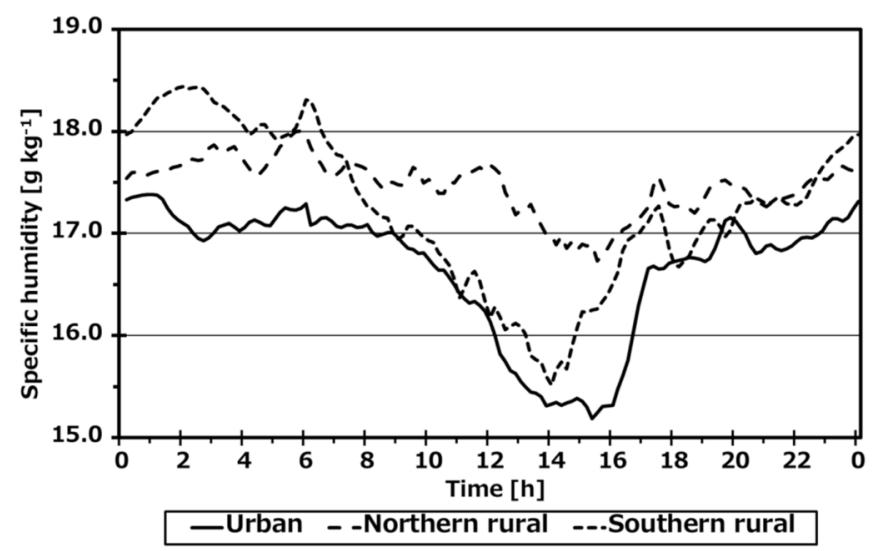

Figure 11. Diurnal variations in specific humidity averaged over urban (solid line), northern rural (dashed line), and southern rural points (dotted line). 
sonal variations in Kumagaya are compared with reports from other cities. The daytime UHII in Kumagaya was large in summer and small in winter. However, other urban areas have reported frequent cool island occurrences during the day in summer (Gaffin et al. 2008; Shigeta and Ohashi 2009; etc.). Kondoh and Kaihotsu (1995) and Sugawara et al. (2006) cited shading by buildings as one of the factors causing cool islands during the daytime. The buildings in the urban areas of Kumagaya are generally lower than those in cities reporting cool islands. Therefore, it is presumed that the cooling effect from shading by buildings is smaller in Kumagaya than in other cities.

Land cover in the rural area of Kumagaya is dominated by crop fields, forests, and paddy fields. In contrast, many previous studies compare urban and suburban temperatures. It is presumed that temperatures in these areas do not differ as much in summer due to a small difference in ground surface and in heat balance between urban and suburban. In UHII calculation, taking the rural land cover into consideration may explain the difference between the results of this and previous studies. In response to this problem, Stewart and Oke (2012) proposed subdividing each urban and suburban landscape on a several-hundred-meter scale for use in quantitative analysis of urban observation data. These findings suggest that land use in surrounding suburbs must be well considered in order to compare UHIs in various cities.

\section{Seasonal variations in nighttime UHII}

This section focuses on factors that contribute to the seasonal variation of nighttime UHII. The nighttime UHII in Kumagaya is the smallest in summer (with a minimum of $0.7^{\circ} \mathrm{C}$ in June) and the largest in spring (with a maximum of $1.2^{\circ} \mathrm{C}$ in May). However, it is reported that the nighttime UHII in many cities of Japan shows the maximum in winter (see for example: Sakakibara 1991; Shigeta and Ohashi 2009), contradicting the observational results of this study. Therefore, the factors contributing to larger nighttime UHII in Kumagaya in April and May are discussed. It has been suggested that the nighttime UHII widely varies depending on weather conditions (Oke and Maxwell 1975). The formation of a surface inversion layer in rural areas is important for the development of the nighttime UHII. Therefore, this section outlines the seasonal meteorological changes in Kumagaya that might relate to the formation of a surface inversion layer.

Figure 12 shows the seasonal variation of monthly cumulative precipitation from March 2014 to February 2015 at the Kumagaya Meteorological Observatory. In summer, much precipitation was associated with local mesoscale circulation, and values for both total precipitation and precipitation days were larger than those observed for other seasons. Precipitation was much higher in June and October than during other months, likely because of the effects of the Baiu rain band and typhoon season, respectively. Precipitation during winter was less than that during summer due to a dry northwesterly air flow. Precipitation during spring was also less than that during summer due to frequent passages of synoptic-scale high-pressure systems. The frequency of travelling high-pressure systems was especially high in the spring of 2014, resulting in values of total precipitation and precipitation days of about $100 \mathrm{~mm}$ and 7 days, respectively, which were smaller than the normal year values.

Figure 13 shows seasonal variations of the monthly average specific humidity at the Kumagaya Meteorological Observatory. The specific humidity was higher in summer than in other seasons, with a maximum of $16.5 \mathrm{~g} \mathrm{~kg}^{-1}$ in August. Such a high specific humidity in summer was attributed to enhanced precipitation

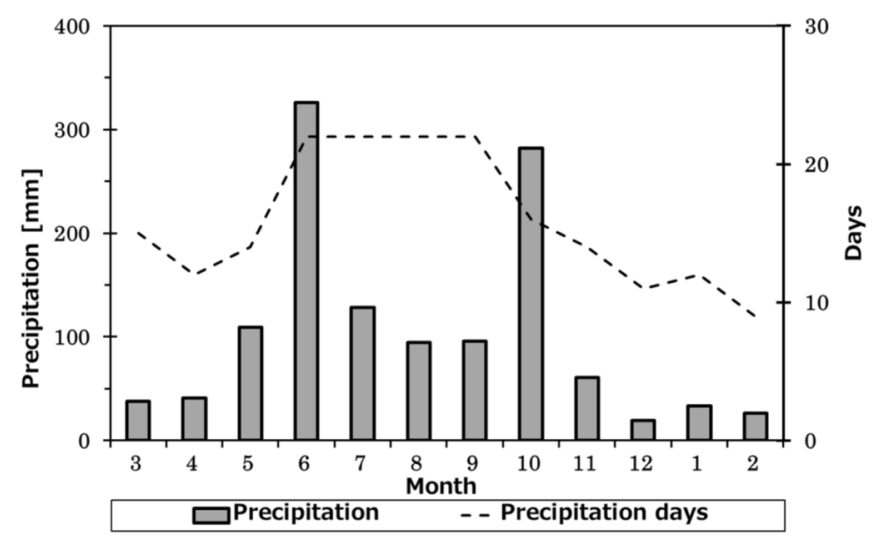

Figure 12. Seasonal variations in monthly cumulative precipitation (bar) and precipitation days (dashed line) from March 2014 to February 2015 at the Kumagaya Meteorological Observatory. 
and moist southerly wind from the western north Pacific subtropical high. These findings suggest that the nighttime UHII remains small in summer because radiation cooling is suppressed by abundant water vapor in the nighttime.

Precipitation and specific humidity were the lowest in winter, but UHII was smaller in winter than in spring. Thus it is difficult to explain the seasonal variation of UHII in the nighttime only by precipitation and specific humidity. Oke (1976) reported that the UHII is smaller during strong winds than during weak winds, and he suggested that strong winds cause surface inversion breakup and increase horizontal warm-air advection from the urban area. Figure 14 shows seasonal variations in wind speed and wind direction at the Kumagaya Meteorological Observatory. The seasonal variations in wind are shown in the monthly average for all days and sunny days. During all-weather days, the wind direction generally ranges from north to west (except during summer), and the wind speed in winter was $\sim 1 \mathrm{~ms}^{-1}$ larger than that during other seasons on average. A maximum wind speed of $3.2 \mathrm{~ms}^{-1}$ was observed in January.
Compared to all-weather averages, the wind speed average for sunny days was $0.3 \mathrm{~ms}^{-1}$ smaller during AprilMay and $0.3 \mathrm{~ms}^{-1}$ larger during the winter. These findings suggest that the nighttime UHII is suppressed under strong northwesterly flow in winter, and enhanced by the frequent passage of synoptic-scale high-pressure systems in spring, which favors the development of the surface inversion layer. Thus, nighttime UHII is larger in spring than in winter.

Finally, the seasonal variation of nighttime UHII in Kumagaya is compared with reports from other cities. It was suggested that the seasonal variation of UHII in Kumagaya contributed greatly to phenomena above the synoptic scale (for example, migratory anticyclone and airflow over the mountain). Chow and Roth (2006) reported maximum and minimum UHIIs in Singapore in summer and winter, respectively. They attributed this pattern to dry summers and rainy winters under the influence of the monsoon. Kim and Baik (2005) showed that the UHII in Seoul, South Korea was at a maximum in autumn and a minimum in summer. They suggest that these climatological characteristics are related to the mon-

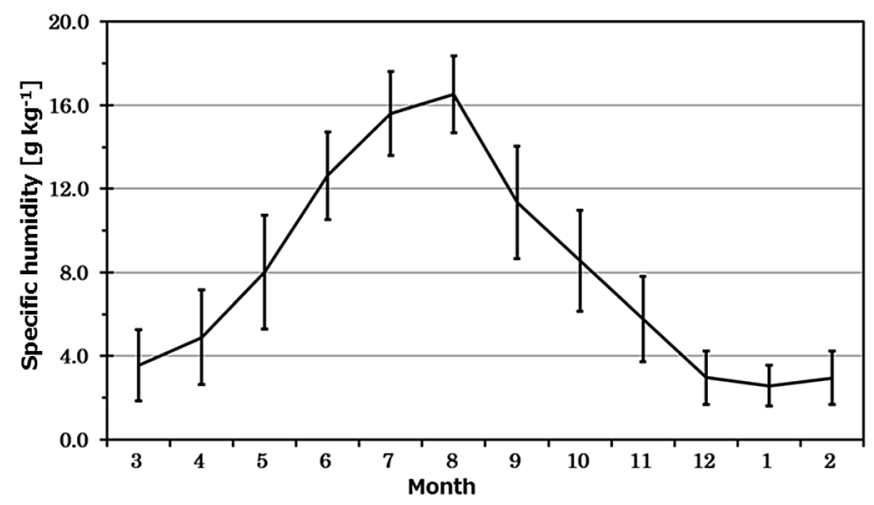

Figure 13. Seasonal variation in the monthly-mean specific humidity at the Kumagaya Meteorological Observatory, with standard deviations shown by error bars.

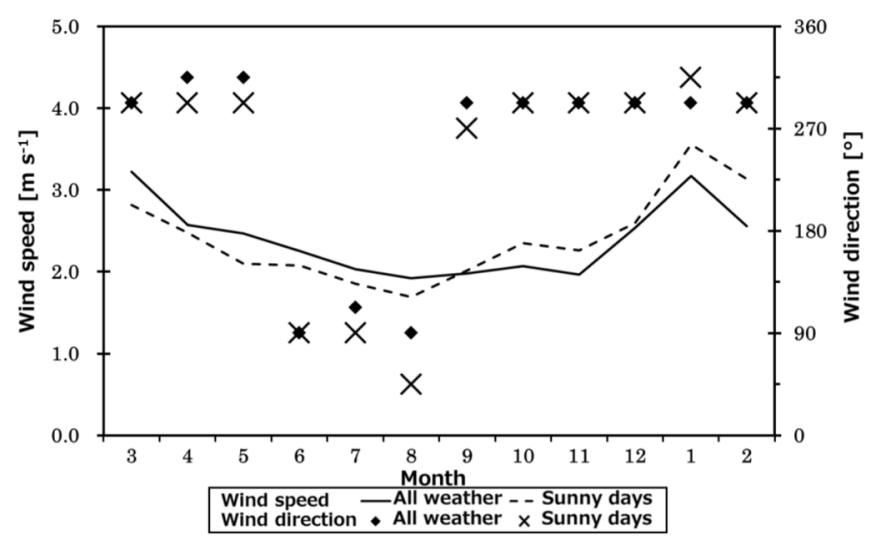

Figure 14. Seasonal variations in wind speed and wind direction at the Kumagaya Meteorological Observatory. Lines denote the wind speed averaged monthly over all weather (solid) and sunny days (dashed), and symbols denoting the wind direction averaged monthly over all weather (diamond) and sunny days (cross). 
soon climate, and report results quite similar to those in this study.

\section{Conclusions}

In this study, long-term, multiple fixed-point surface air temperature observations were performed in Kumagaya, a mid-scale city, and seasonal variations in the UHI were discussed. The main results of this study are as follows:

(1) Horizontal distributions of observed surface air temperatures in Kumagaya indicate that the UHI is more apparent at nighttime than in the daytime in all seasons. They also show that the daytime UHI is more apparent in summer, whereas the nighttime UHI is more apparent in winter.

(2) Daytime UHII values in Kumagaya are maximized in summer and minimized in winter. This characteristic is more evident during sunny days. Additional observations of specific humidity during sunny days in summer suggested that the difference in the surface heat balance between urban and rural areas greatly contributes to the temperature difference between the two.

(3) The nighttime UHII in Kumagaya is maximized in April-May, in contrast to other cities. This observation may be explained by strong northwesterly airflow over the mountains during winter and frequent calm, sunny days due to migratory anticyclone during April-May.

However, the observation presented in this study is limited to a one-year period, and thus this may not be enough to represent the climatological characteristics of the UHI in Kumagaya. Therefore, in order to obtain more general conclusions, further long-term observations and numerical simulations are necessary.

\section{Acknowledgements}

We would like to express our gratitude to the personnel of Kumagaya, Fukaya, Gyoda, and Konosu city offices, who provided the installation sites for our fixed-point observations. We thank Dr. Suzuki-Parker of the Rissho University for her helpful advice and assistance with this manuscript.

\section{References}

Ackerman, B. 1985. Temporal march of the Chicago heat island. Journal of Climate and Applied Meteorology 24: 547-554.

Chow, W. T. and Roth, M. 2006. Temporal dynamics of the urban heat island of Singapore. International Journal of Climatology
26: $2243-2260$.

Gaffin, S. R., Rosenzweig, C., Khanbilvardi, R., Parshall, L., Mahani, S., Glickman, H., Goldberg, R., Blake, R., Slosberg, R. B. and Hillel, D. 2008. Variations in New York city's urban heat island strength over time and space. Theoretical and Applied Climatology 94: 1-11.

Kawamura, T. 1964. Analysis of the temperature distribution in the Kumagaya city: A typical example of the urban climate of a small city. Geographical Review of Japan 37: 243-254. (JE)

Kikegawa, Y., Genchi, Y., Kondo, H. and Hanaki, K. 2006. Impacts of city-block-scale countermeasures against urban heat-island phenomena upon a building's energy-consumption for airconditioning. Applied Energy 83: 649-668.

Kim, Y. H. and Baik, J. J. 2005. Spatial and temporal structure of the urban heat island in Seoul. Journal of Applied Meteorology 44: 591-605.

Kondoh, A. and Kaihotsu, I. 1995. Relating the observed brightness temperature by Landsat to the air temperature distributions and the structure of urban canopy layer in Hiroshima city, Japan. The Journal of Geography 104: 225-238. (JE)

Kusaka, H., Takane, Y., Abe, S., Takaki, M., Shigeta, Y., Ohashi, Y. and Baoyin, B. 2012. Urban heat island phenomenon observed in open spaces in Tsukuba city on clear summer days: An evaluation of uncertainty in urban-rural temperature difference. Journal of Heat Island Institute International 7: 1-9. (JE)

Kuwagata, T., Ishigooka, Y., Fukuoka, M., Yoshimoto, M., Hasegawa, T., Usui, Y. and Sekiguchi, T. 2014. Temperature difference between meteorological station and nearby farmland: Case study for Kumagaya city in Japan. Scientific Online Letters on the Atmosphere 10: 45-49.

Matsumoto, F., Fukuoka, Y. and Goto, S. 2002. Change in heat island pattern due to change of urban form and structure in Kumagaya city. Papers on Environmental Information Science 16: 387-392. (J)

Nakamura, Y. and Shigeta, Y. 2014. Extraction of diurnal variation patterns of the heat island intensity by the fixed point observation and multivariate analysis: In August, 2013 in Kumagaya city, Saitama, Prefecture. Papers on Environmental Information Science 28: 379-384. (J)

Oke, T. R. 1973. City size and the urban heat island. Atmospheric Environment 7: 769-779.

Oke, T. R. 1976. The distinction between canopy and boundarylayer heat islands. Atmoshere 14: 268-277.

Oke, T. R. 1978. Boundary layer climates. Methuen: New York.

Oke, T. R. 1981. Canyon geometry and the nocturnal urban heat island: Comparison of scale model and field observations. International Journal of Climatology 1: 237-254.

Oke, T. R. 1982. The energetic basis of the urban heat island. Quarterly Journal of the Royal Meteorological Society 108: 124.

Oke, T. R. and Maxwell, G. B. 1975. Urban heat island dynamics in Montreal and Vancouver. Atmospheric Environment 9: 191-200.

Oku, Y. and Masumoto, K. 2014. An observational study of the difference on urban heat islands between summer and winter in Osaka city. Journal of Heat Island Institute International 9: 1-12. (JE) 
Sakakibara, Y. 1991. Heat island intensity in Koshigaya: A case study of the rural with the paddy field. TENKI 41: 515-523. (J)

Sakakibara, Y. and Owa, K. 2005. Urban-rural temperature differences in coastal cities: Influence of rural sites. International Journal of Climatology 25: 811-820.

Shigeta, Y. and Ohashi, Y. 2009. Analysis of heat island intensity from meteorological observation network in Okayama city. TENKI 56: 443-454. (J)

Shochat, E., Warren, P. S., Faeth, S. H., McIntyre, N. E. and Hope, D. 2006. From patterns to emerging processes in mechanistic urban ecology. Trends in Ecology \& Evolution 21: 186-191.

Stewart, I. D. and Oke, T. R. 2012. Local climate zones for urban temperature studies. Bulletin of the American Meteorological Society 93: 1879-1900.

Sugawara, H., Narita, K., Mikami, T., Honjo, T. and Ishii, K. 2006.
Cool island intensity in a large urban green: Seasonal variation and relationship to atmospheric condition. TENKI 53: 393-404. (JE)

Takane, Y. and Kusaka, H. 2011. Formation mechanisms of the extreme high surface air temperature of $40.9^{\circ} \mathrm{C}$ observed in the Tokyo metropolitan area: Considerations of dynamic foehn and foehnlike wind. Journal of Applied Meteorology and Climatology 50: 1827-1841.

Tan, J., Zheng, Y., Tang, X., Guo, C., Li, L., Song, G., Zhen, X., Yuan, D., Kalkstein, A. J., Li, F. and Chen, H. 2010. The urban heat island and its impact on heat waves and human health in Shanghai. International Journal of Biometeorology 54: 75-84.

(J) written in Japanese

(JE) written in Japanese with English abstract 